Journal of Systems Science and Information

Jun., 2016, Vol. 4, No. 3, pp. 235-243

DOI: $10.21078 /$ JSSI-2016-235-09

\title{
Does Medical Insurance Improve Household Consumption in China? - A Re-analysis Based on Meta Regression Analysis
}

\author{
Jian CHAI \\ International Business School, Shaanxi Normal University, Xi'an 710119, China; \\ School of Economics and Management, Xidian University, Xi'an 710126, China \\ Limin $\mathrm{XING}^{\dagger}$ \\ International Business School, Shaanxi Normal University, Xi'an 710119, China \\ E-mail: xinglm0219@163.com \\ Ying YANG \\ International Business School, Shaanxi Normal University, Xi'an 710119, China \\ Kin Keung LAI \\ International Business School, Shaanxi Normal University, Xi'an 710119, China; \\ Department of Management Sciences, City University of Hong Kong, Hong Kong, China
}

\begin{abstract}
In recent years, it has been a hot pot to explore the effectiveness of basic medical insurance. However, due to different sample characteristics, time series length, models and so on used by authors, there exists big difference among relevant papers. In this paper, we try to apply meta regression analysis (MRA, a prevalent statistic literature review method) to explore its influence on family expenditure, and 90 sample observations were extracted from 49 important literatures. We find: 1) All the index construction, sample characteristic, model selection, control factors will influence the conclusions of medical insurance effectiveness; 2) The implement of basic medical insurance will increase household consumption other than the new rural cooperative systems; 3) The implement of basic health insurance has not really reduce family's medical expense. Thus, we induce that adverse selection exists in China's medical insurance.
\end{abstract}

Keywords medical insurance; household consumption; meta-regression analysis

\section{Introduction}

There is no denying the fact population aging is increasing alarming in China. According to China Statistics Bureau, people over 60 years old share almost $15 \%$ by 2013, more than 2 billion. However, the aged is more likely to suffer from chronic disease and is the main beneficiary from basic medical insurance meanwhile. Under this background, poor access to healthcare and high fee in fact are the two major problems facing China's health system, which have become the

Received November 24, 2015, accepted March 14, 2016

Supported by the National Natural Science Foundation of China (71473155); Theme Based Research Grant, RGC of Hong Kong (8770001)

$\dagger$ The corresponding author 
two major factors handicapping social stability and economic development. In order to reduce the heavy burden on residents, Chinese government successively put forward medical insurance for urban workers in 1998, new rural cooperative medical system (2003) and medical insurance for urban residents (2007). Whether the three kinds of health insurances are helpful to increase people's consumption and reduce their precautionary saving? To be frank, there have been plenty of published papers exploring the effect of medical insurance on household consumption, medical expense, mortality of the old. However, whether the influence is significant or not, positive or negative differ from different scholars (Gan and Liu, et al. ${ }^{[1]}, \mathrm{Xie}^{[2]}$ ).

Thus, the policy makers might be confused for the effectiveness of the medical insurance. In this context, it is of great necessity to figure out what factors lead to the inconsistent conclusions for the previous papers and the real effect of medical insurance. Meta-regression analysis (MRA) is appropriate to analyze the impact of "Misspecialization Bias" on empirical results, which is a more reliable and scientific quantitative literature review method and can help researches identify the accuracy of previous empirical findings. In this paper, the authors applied MRA to explore its influence on family expenditure, and 90 sample observations were extracted from 49 important literatures. Finally, we draw three important conclusions: 1) All the index construction, sample characteristic, model selection, control factors will influence the conclusions of medical insurance effectiveness; 2) The implement of basic medical insurance will increase household consumption other than the new rural cooperative systems; 3) The implement of basic health insurance has not reduce family's medical expense, thus we conclude that adverse selection exists in medical insurance.

The rest of the paper is organized as follows. Section 2 summaries the previous research results and introduce the theoretical meta-regression specification and its application in this paper. In Section 3, we describe how we get data from papers downloaded in the CNKI and Elsevier Science Direct, and define all the independent variables and dependent variables. Next we build meta-regression model and discuss the empirical results in Section 4. The last section is conclusion.

\section{Literature Review}

Concerning the impact of healthcare on family total consumption, $\mathrm{Li}^{[3]}$ built DID model and concluded that the basic medical insurance increase total household consumption by $37.32 \%$. Zhao ${ }^{[4]}$ used OLS to research on the impaction of medical insurance for urban workers on household total consumption, also find that the influence is significant and positive ${ }^{[5-8]}$. Bai and $\mathrm{Wu}^{[9]}$ discussed the implement of new rural cooperation on residents' household expenditure, established DID model and conduct counterfactual match test to eliminate the endogeneity, finally concluded it leaded to a 5.6 significant percent increase on household consumption except for medical expense (Zang and Liu, et al. ${ }^{[10]}$ ). Cheung and Padieu ${ }^{[11]}$ found that new rural cooperative medical system (NCMS) has a negative impact on middle-income savings but does not affect the poorest participants. NCMS also decreases richest participants' savings, when they do not benefit from other health programs. Thus, the implementation of a healthcare scheme appears to be an appropriate tool to lower savings and boost consumption and so sustain economic growth. 
Another important aspect is exploring the effect of medicare on one's medical expense, for this point, $\mathrm{Su}$ and $\mathrm{Li}$, et al. ${ }^{[12]}$ built two-part model with 2009 survey data, model and found that the new rural cooperative medical care system in a certain degree enhance the rural residents' clinical consultation probability and reduce their medical expenses (Xue and $\mathrm{Lu}^{[13]}$ ); but raise one's medical expense for people who take part in medical insurance for urban workers; and no significant implications for medical insurance for urban residents. However, other scholars drew diverse conclusions in view of this, i.e., Lai ${ }^{[14]}$ discovered that medical insurance makes it more accessible for the old to accept diagnose, but had not alleviate their medical burden. Wen and Song ${ }^{[15]}$ also found the new rural cooperation increase the old one's medical expense for 19 percent. By building sample selection model, Huang and Gan ${ }^{[16]}$ concluded that people participate in medical insurance for urban workers, their total medical expense reduce $28.6 \% \sim 30.6 \%$.

In 1989, Stanley and Jarrel ${ }^{[17]}$ put forward meta-regression analysis (MRA), which develop the economics branch for meta-analysis, which is exactly appropriate for solving the problem mentioned above. MRA is a kind of quantitative literature review method based on regression model. It could find out the factors that induce inconsistent empirical results, and degree of inconsistence. Meta-analysis is mainly applied to psychology and medicine, while MRA is widely used in economics and focuses on exploring the reasons why the results are conflicting. In recent years, MRA is gradually accepted by scholars at home (Peng, et al. ${ }^{[18]}$ ). Huang and $\operatorname{Lin}^{[19]}$ applied this model to research inconsistent consequences for capital-energy substitution problem exists in China's industry section. MRA results denote that research conclusions are significantly influenced by constant returns to scale hypothesis, but not by factor marketing regulation. When studying the spillover effect for FDI, Zhang, Zhao ${ }^{[20]}$ and Wang ${ }^{[21]}$ as well used MRA, and came to some conclusions of reference.

In this paper, we intend to build MRA to figure out the resource for what factors lead to different conclusions when study on the influence of healthcare insurance on household expenditure and medical expenditure, and others.

\section{Data and Variable Specification}

In CNKI and Elsevier Science Direct, under the options of "subject" and "key words", the authors respectively input words, i.e., basic medical insurance, healthcare insurance, household consumption, medical expense, family expenditure, as a consequence, we totally download 237 related papers. Then following four criterions: 1) The paper must be empirical; 2) Leave out papers published in different languages but have the same content; 3) Exclude papers aimed at commercial medical insurance rather than the 3 basic medical insurances, we finally screen out 49 adequate articles. Specifically, 90 conclusions were extracted from these papers.

In meta-regression analysis, the dependent variable, namely effect size, is taken from the original papers, usually including dummy variables, such as the significance or the signs of the parameters, $t$-statistic, parameter coefficients, and elasticity, and so on. The independent variable is the characteristic variable taken from published papers, including index selection, sample size, data range, estimation method and so on. According to the Görg ${ }^{[22]}$ and Wooster ${ }^{[23]}$ 's description, this article apply meta regression analysis to explore what factors influence the 
significance and plus-minus of China's medical insurance reform effectiveness, MRA equation is set as follows:

$$
\mathrm{ES}_{i}=\beta_{0}+\sum_{j} \beta_{j} \mathrm{IC}_{i j}+\sum_{k} \beta_{k} \mathrm{SC}_{i k}+\sum_{l} \beta_{l} \mathrm{MS}_{i l}+\sum_{m} \beta_{m} \mathrm{CF}_{i m}+\varepsilon_{i}, \quad i=1,2,3,
$$

where $\mathrm{ES}_{i}$ (Effect size) denotes the dependent variable $i$, IC (Index construction), SC (Sample characteristic), MS (Model selection), CF (Control factors) respectively stands for 4 kinds of independent variables, and $j, k, l, m$ separately signify the total frequency of independent variables. $\beta$ is parameter estimator in this paper, and $\varepsilon$ is the random disturbance term. Three main dependent variables are composed in the meta regression analysis: 1) $Y_{1}$ : The significance of parameter coefficient, if significant, $Y_{1}=1$, if not, $Y_{1}=0$. 2) $Y_{2}$ : The plus-minus of parameter coefficient, if plus, $Y_{2}=1$, if not, $Y_{2}=0$. 3) $Y_{3}$ : The $t$-statistic of parameter coefficient, $Y_{3 P}$ is the positive $t$-statistic, $Y_{3 N}$ is the negative $t$-statistic, $Y_{3 A}$ is the absolute value of $t$-statistic.

Table 1 Independent variables for MRA

\begin{tabular}{|c|c|c|c|}
\hline $\begin{array}{l}\text { Orientation } \\
\text { indicators }\end{array}$ & $\begin{array}{l}\text { Item } \\
\text { indexes }\end{array}$ & Indicators description & Frequency \\
\hline \multirow{9}{*}{$\begin{array}{l}\text { Index } \\
\text { construction }\end{array}$} & $X_{1}$ & Dependent variable is household consumption & 18 \\
\hline & $X_{2}$ & Dependent variable is medical expense & 39 \\
\hline & $X_{3}$ & Dependent variable is non-medical expense & 9 \\
\hline & $X_{4}$ & Dependent variable is out-of-pocket medical expense & 11 \\
\hline & $X_{5}$ & Dependent variable is illness direct economic burden & 12 \\
\hline & $X_{6}$ & new rural cooperative insurance (NRC) & 18 \\
\hline & $X_{7}$ & medical insurance for urban workers (UW) & 12 \\
\hline & $X_{8}$ & medical insurance for urban residents (UR) & 25 \\
\hline & $X_{9}$ & All the three medical insurances are researched & 25 \\
\hline \multirow{5}{*}{$\begin{array}{l}\text { Sample } \\
\text { characteristic }\end{array}$} & $X_{10}$ & Time span for sample observations & / \\
\hline & $X_{11}$ & Sample average time length & / \\
\hline & $X_{12}$ & $\operatorname{Ln}(\sqrt{ } N), N$ stands for the number of sample in the & / \\
\hline & $X_{13}$ & Family or individual data is used in the literature & 78 \\
\hline & $X_{14}$ & Research object is the aged & 41 \\
\hline \multirow{4}{*}{$\begin{array}{l}\text { Model } \\
\text { selection }\end{array}$} & $X_{15}$ & Sample selection model & 28 \\
\hline & $X_{16}$ & Difference in difference model (DID) & 17 \\
\hline & $X_{17}$ & Fixed effect Tobit model is used & 14 \\
\hline & $X_{18}$ & OLS & 31 \\
\hline \multirow{3}{*}{$\begin{array}{l}\text { Control } \\
\text { factors }\end{array}$} & $X_{19}$ & $\begin{array}{l}\text { Personal factors are included (age, sex, education } \\
\text { background, marital status) }\end{array}$ & 70 \\
\hline & $X_{20}$ & $\begin{array}{l}\text { Demand factors are included (Self-reported health, suffering } \\
\text { from chronic diseases or not) }\end{array}$ & 61 \\
\hline & $X_{21}$ & $\begin{array}{l}\text { Enabling factors are included (Income, education } \\
\text { level, profession) }\end{array}$ & 76 \\
\hline
\end{tabular}

Table 1 shows the independent variables, corresponding interpretation, and frequency appearing in the literatures. We divide 21 variables into four aspects: Index construction, sample 
characteristic, model selection, and control factors.

\section{Empirical Results and Discussion}

Table 2 presents the MRA results when the dependent variable denote the significance of basic insurance's effect. We just retain the factors at least $10 \%$ significance level and get rid of insignificant ones. In order to get more reliable outcome, we compare with three regression methods (probit, logit, extreme-value). As showed in the table, for all the equations (2.1), (2.2), and (2.3), coefficient for $X_{12}$ is positive at $1 \%$ significance level, and $X_{15}$ are positive at $10 \%$ significance level, indicating that if the literature use big sample data and sample selection method, it is more likely to draw a conclusion that the medical insurance is effective for household consumption. On the one hand, when the sample range is large, estimating error will be narrowed. On the other hand, the selection equation added in sample selection model could eliminate the selection bias, which is more appropriate. Conversely, coefficient for $X_{2}$, $X_{4}, X_{13}$ are significantly negative, indicating that if the authors use medical expense and outof-pocket medical expense as dependent variables, use family and individual data, it is more likely to draw a conclusion that the medical insurance is ineffective. The results are worthy of note, it may give a signal that the implement of basic health insurance actually have not reduce household's medical expense.

Table 2 The MRA results for whether the dummy is significant or not

\begin{tabular}{|c|c|c|c|c|c|c|}
\hline \multirow{2}{*}{ Variables } & \multicolumn{2}{|c|}{$(2.1)$} & \multicolumn{2}{|c|}{$(2.2)$} & \multicolumn{2}{|c|}{$(2.3)$} \\
\hline & Coefficient & $z$-statistic & Coefficient & $z$-statistic & Coefficient & $z$-statistic \\
\hline $\mathrm{C}$ & 0.1835 & 0.1252 & -0.2156 & -0.0750 & -0.4583 & 0.1835 \\
\hline$X_{4}$ & $-1.8055^{* *}$ & -2.1071 & $-3.4834^{*}$ & -1.8553 & -3.1965 & $-1.8055^{* *}$ \\
\hline$X_{12}$ & $0.9536^{* * *}$ & 3.0245 & $1.6324^{* * *}$ & 2.7889 & 1.3334 & $0.9536^{* * *}$ \\
\hline$X_{13}$ & $-2.2298^{*}$ & -1.7406 & $-3.8313^{*}$ & -1.6583 & -2.8338 & $-2.2298^{*}$ \\
\hline$X_{14}$ & $-1.0580^{*}$ & -1.9497 & $-1.8739^{*}$ & -1.7394 & -1.5552 & $-1.0580^{*}$ \\
\hline$X_{15}$ & $1.2839^{*}$ & 1.6199 & 2.6350 & 1.4399 & 2.5178 & $1.2839^{*}$ \\
\hline $\begin{array}{c}\text { Dependent } \\
\text { variable }\end{array}$ & \multicolumn{2}{|c|}{$Y_{1}$} & \multicolumn{2}{|c|}{$Y_{1}$} & \multicolumn{2}{|c|}{$Y_{1}$} \\
\hline Method & \multicolumn{2}{|c|}{ Probit } & \multicolumn{2}{|c|}{ Logit } & \multicolumn{2}{|c|}{ Extreme-value } \\
\hline Observations & \multicolumn{2}{|c|}{90} & \multicolumn{2}{|c|}{90} & \multicolumn{2}{|c|}{90} \\
\hline McFadden $R^{2}$ & \multicolumn{2}{|c|}{0.29} & \multicolumn{2}{|c|}{0.294} & \multicolumn{2}{|c|}{0.308} \\
\hline LR statistic & \multicolumn{2}{|c|}{29.041} & \multicolumn{2}{|c|}{29.458} & \multicolumn{2}{|c|}{30.854} \\
\hline Prob & \multicolumn{2}{|c|}{0.048} & \multicolumn{2}{|c|}{0.043} & \multicolumn{2}{|c|}{0.03} \\
\hline
\end{tabular}

Note: McFadden $R^{2}$ presents the goodness of fit. *: Statistical significance at $10 \%$ level. **: Statistical significance at $5 \%$ level. ${ }^{* * *}$ Statistical significance at $1 \%$ level.

Table 3 shows the MRA results for whether the dummy is positive or negative. As can be seen from Equation (3.1), (3.2) and (3.3) in the table, controlling factors $X_{19}, X_{20}, X_{21}$ are significant at $10 \%$ or $1 \%$ level, which mean the introduce of control factors will lead to different 
results. $X_{11}$ and $X_{16}$ are significantly positive, indicating that if the basic health insurance has imposed for a long time and the author use DID method to eliminate endogeneity, it is more likely to draw a conclusion that the medical insurance will improve household consumption. Conversely, the coefficient of $X_{6}, X_{12}, X_{15}$ are significantly negative, indicating that if the literature's research object is new rural cooperative medical systems, the sample observation is large and build sample selection model, it is more likely to draw a conclusion that the medical insurance will not increase household consumption.

Table 3 The MRA results for whether the dummy is positive or negative

\begin{tabular}{|c|c|c|c|c|c|c|}
\hline \multirow{2}{*}{ Variables } & \multicolumn{2}{|c|}{$(3.1)$} & \multicolumn{2}{|c|}{$(3.2)$} & \multicolumn{2}{|c|}{$(3.3)$} \\
\hline & Coefficient & $z$-statistic & Coefficient & $z$-statistic & Coefficient & $z$-statistic \\
\hline$X_{6}$ & $-1.86179^{* * *}$ & -3.046 & $-3.1934^{* * *}$ & -2.6491 & $-2.2241^{* * *}$ & -2.6854 \\
\hline$X_{11}$ & $0.2304^{*}$ & 1.9009 & $0.3954^{*}$ & 1.6645 & $0.2723^{*}$ & 1.7718 \\
\hline$X_{12}$ & $-0.8545^{* * *}$ & -2.9690 & $-1.4538^{* * *}$ & -2.8293 & $-1.2425^{* *}$ & -2.5143 \\
\hline$X_{15}$ & $-1.3155^{* *}$ & -2.2479 & $-2.2058^{* *}$ & -2.1111 & $-1.5324^{*}$ & -1.6942 \\
\hline$X_{16}$ & $1.5476^{*}$ & 1.6587 & 2.6624 & 1.5348 & 2.0017 & 1.5439 \\
\hline$X_{19}$ & $1.1483^{*}$ & 1.6656 & $1.9775^{*}$ & 1.6364 & 1.4163 & 1.5108 \\
\hline$X_{20}$ & $1.2906^{* * *}$ & 2.5936 & $2.1290^{* * *}$ & 2.3805 & $1.6689^{*}$ & 1.9498 \\
\hline $\begin{array}{c}\text { Dependent } \\
\text { variable }\end{array}$ & \multicolumn{2}{|c|}{$Y_{2}$} & \multicolumn{2}{|c|}{$Y_{2}$} & \multicolumn{2}{|c|}{$Y_{2}$} \\
\hline Method & \multicolumn{2}{|c|}{ Probit } & \multicolumn{2}{|c|}{ Logit } & \multicolumn{2}{|c|}{ Extreme-value } \\
\hline Observations & \multicolumn{2}{|c|}{90} & \multicolumn{2}{|c|}{90} & \multicolumn{2}{|c|}{90} \\
\hline McFadden $R^{2}$ & \multicolumn{2}{|c|}{0.374} & \multicolumn{2}{|c|}{0.327} & \multicolumn{2}{|c|}{0.361} \\
\hline LR statistic & \multicolumn{2}{|c|}{41.739} & \multicolumn{2}{|c|}{40.929} & \multicolumn{2}{|c|}{40.268} \\
\hline Prob & \multicolumn{2}{|c|}{0.001} & \multicolumn{2}{|c|}{0.002} & \multicolumn{2}{|c|}{0.002} \\
\hline
\end{tabular}

Note: McFadden $R^{2}$ presents the goodness of fit. *: Statistical significance at $10 \%$ level. **: Statistical significance at $5 \%$ level. ${ }^{* * *}$ Statistical significance at $1 \%$ level.

As mentioned in Section 3, another dependent variable is the t-statistic value obtained from the original empirical literatures. Table 4 demonstrates the corresponding MRA results (insignificant outcomes are not displayed here, for which the authors explore stepwise forwards method to estimate three equations. In Equation (4.3), the absolute $t$ value is significant when encompassing following variables $X_{5}$ (dependent variable is direct economic burden of illness), $X_{9}$ (all the three medical insurances are researched), $X_{14}$ (research object is the aged), $X_{19}$ (personal factors are included), $X_{21}$ (enabling factors are included like income, education level and profession), which denote it is more likely to obtain significant results if the empirical analysis took direct economic burden of illness as dependent variables, added comprehensive control factors, and focused on the aged. For Equation (4.1), if the estimates are positive, it indicates that when introducing such factors, it is more likely to obtain results that the basic healthcare will improve household's total consumption, for which including variables $X_{12}$ (sample size), $X_{15}$ (Sample selection model is used in the literature), $X_{17}$ (Fixed effect Tobit 
model is used). On one hand, it makes sense that the larger sample range will achieve more accurate consequences; on the other hand, it is preferable to adopt sample selection and fixed effect Tobit models, for they can eliminate selective bias and endogenous problems in the process of seeking medical advice. Otherwise, for variables $X_{9}$ (All the three medical insurances are researched) $X_{18}$ (OLS is used), their estimates are negative appearing in Equation (4.2), manifesting the incorporation of these variables makes is more possible to draw such conclusions that the medical insurance could reduce one's medical expense. Whereas, the coefficients of $X_{8}$ (Research object is UR), $X_{10}$ (Time span of sample in the literature), $X_{11}$ (The average length of sample in the literature) is positive in Equation (4.2), demonstrating that it will decrease the significance of $t$-statistic value when introducing these variables.

Table 4 The MRA results for the dependent is $t$-statistic value

\begin{tabular}{|c|c|c|c|c|c|c|}
\hline \multirow{2}{*}{ Variables } & \multicolumn{2}{|c|}{$(4.1)$} & \multicolumn{2}{|c|}{$(4.2)$} & \multicolumn{2}{|c|}{$(4.3)$} \\
\hline & Coefficient & $t$-statistic & Coefficient & $t$-statistic & Coefficient & $t$-statistic \\
\hline$X_{4}$ & $-3.4254^{* * *}$ & -2.7193 & $13.1020^{* *}$ & 2.4186 & & \\
\hline$X_{5}$ & $2.5643^{*}$ & 1.7572 & $-10.3931^{* *}$ & -2.7345 & $9.4046^{* * *}$ & 5.9643 \\
\hline$X_{8}$ & & & $6.3472^{*}$ & 1.8689 & & \\
\hline$X_{9}$ & & & $-13.3768^{* * *}$ & -3.3250 & $2.6821^{* *}$ & 2.3035 \\
\hline$X_{10}$ & & & $1.3565^{*}$ & 2.0796 & & \\
\hline$X_{11}$ & & & $2.0561^{* * *}$ & 2.9242 & & \\
\hline$X_{12}$ & $1.1627^{* * *}$ & 3.5895 & & & & \\
\hline$X_{13}$ & $-2.9758^{*}$ & -1.9516 & & & & \\
\hline$X_{14}$ & & & & & $2.8131^{* *}$ & 2.2455 \\
\hline$X_{15}$ & $2.8662^{* * *}$ & 2.8094 & & & & \\
\hline$X_{17}$ & $2.1243^{* *}$ & 2.1323 & & & & \\
\hline$X_{18}$ & & & $-5.6224^{* *}$ & -2.1554 & & \\
\hline$X_{19}$ & & & & & $-3.3348^{*}$ & -1.9713 \\
\hline$X_{21}$ & $1.9745^{* *}$ & 2.4718 & & & $4.1651^{* *}$ & 2.5371 \\
\hline $\begin{array}{c}\text { Dependent } \\
\text { variable }\end{array}$ & \multicolumn{2}{|c|}{$Y_{3 P}$} & \multicolumn{2}{|c|}{$Y_{3 N}$} & \multicolumn{2}{|c|}{$Y_{3 A}$} \\
\hline Method & \multicolumn{2}{|c|}{ Stepwise forwards } & \multicolumn{2}{|c|}{ Stepwise forwards } & \multicolumn{2}{|c|}{ Stepwise forwards } \\
\hline Observations & \multicolumn{2}{|c|}{61} & \multicolumn{2}{|c|}{29} & \multicolumn{2}{|c|}{90} \\
\hline$R^{2}$ & \multicolumn{2}{|c|}{0.436} & \multicolumn{2}{|c|}{0.754} & \multicolumn{2}{|c|}{0.463} \\
\hline F statistic & \multicolumn{2}{|c|}{7.656} & \multicolumn{2}{|c|}{7.653} & \multicolumn{2}{|c|}{7.661} \\
\hline Prob & \multicolumn{2}{|c|}{0.000} & \multicolumn{2}{|c|}{0.000} & \multicolumn{2}{|c|}{0.000} \\
\hline
\end{tabular}

Note: *: Statistical significance at $10 \%$ level. $* *$ : Statistical significance at $5 \%$ level. *** Statistical significance at $1 \%$ level. 


\section{Conclusions}

In this works, the authors build the progressive meta-regression model to figure out the real effect of implement of basic healthcare insurance in past decade on household expenditure and medical expense, and work out what factors lead to different conclusions in terms of empirical results. In accordance with the empirical process and discussion, we come to following conclusions.

1) All the index construction, sample characteristic, model selection and control factors, the authors chose in their studies will influence the conclusions they drew for the effect of medical insurance. We conclude from Table 2 that if the author build sample selection model and the sample scale is large, the medical insurance policy is effective; from Table 3 we conclude if the author build DID model and the policy has been implement for a long time, the medical insurance will improve household consumption. However, under large sample range and sample selection model, new rural cooperative medical systems will not increase the consumption in rural areas. Integrate the results of Table 2 with that in Table 3, we come to a conclusion the basic health insurance is helpful to stimulate consumption other than in the countryside.

2) Moreover, form Table 2 we observe that if the authors use medical expense and outof-pocket medical expense as dependent variables, use family and individual data, it is more likely to draw a conclusion that the medical insurance is ineffective. The results are worthy of note, it probably send a signal that the implement of basic health insurance have not reduce medical expense. Thus, we speculate that adverse selection exists in medical insurance, namely the implement of basic health insurance induce more persons to go to hospital once they got ill and finally increase their medical expense.

3) According to Table 4, we found that it is more likely to obtain significant results if the empirical analysis took out-of-pocket medical expense and direct economic burden of illness as dependent variables, added comprehensive control factors, and focused on the aged. Besides, the larger the sample size, establishing sample selection model and fixed effect Tobit model, it will improve the probability that the basic healthcare will improve household's total consumption.

\section{References}

[1] Gan L, Liu G E, Ma S. Resident basic medical insurance and household current consumption. Economic Research Journal, 2010(Z): 30-38.

[2] Xie E. Health insurance and anti-poverty in urban and rural areas: 1989-2006. Journal of Finance and Economics, 2008, 34(12): 68-83.

[3] Li Y J. The effect of basic medical insurance on household consumption. The Business Circulate, 2012(12): $17-19$.

[4] Zhao K. The impact of the correlation between health expenditure and survival probability on the demand for insurance. European Economic Review, 2015, 75: 98-111.

[5] He X Q, Shi W. Health risk and Chinese urban household's consumption. Economic Research Journal, 2014, 5: 34-48.

[6] Zhou Q, Zang W B, Liu G E. Health insurance coverage and medical financial risks for Chinese households. Insurance Studies, 2013, 7: 95-107.

[7] Zhu M L, Kui C. The effect of health insurance on household consumption: Empirical analysis with panel data at province level. Insurance Studies, 2012, 4: 103-121.

[8] Fan X. The effect of social health insurance on household's consumption. Fiscal Studies, 2011, 5: 43-48.

[9] Bai C E, Wu B. Health insurance and consumption: Evidence from China's new cooperative medical 
scheme. Journal of Comparative Economics, 2014, 42(2): 450-469.

[10] Zang W B, Liu G N, Xu F, et al. The effect of urban resident basic medical insurance on household consumption. Economic Research Journal, 2012, 7: 75-85.

[11] Cheung D, Padieu Y. Heterogeneity of the effects of health insurance on household savings: Evidence from rural China. World Development, 2015, 66: 84-103.

[12] Su C H, Li Q Y, Wang D H. The influence of different basic medical insurance on Chinese residents' medical consumption: Based on the CHNS data. Research on Economics and Management, 2013, 10: 23-30.

[13] Xue W L, Lu J H. A study on effect of medical insurance status on the aged' medical expenses. Population Journal, 2012, 1: 61-67.

[14] Lai G Y. The experience analysis between the elder's medical consumption and the medical security. Social Security Studies, 2012, 6: 46-57.

[15] Wen S J, Song S B. Analysis on medical insurance impact on Chinese rural elders' health demand. Chinese Health Economics, 2013, 32(7): 24-26.

[16] Huang F, Gan L. Excess demand or appropriate demand? — Health insurance, medical care and mortality of the elderly in urban China. Economic Research Journal, 2010, 6: 105-119.

[17] Stanley T D, Jarrel S B. Meta-regression analysis: A quantitative method of literature surveys. Journal of Economic Surveys, 1989, 3(2): 161-170.

[18] Peng Y C, Gu L L. The META regression analysis in economics. Economics Information, 2014, 2: 126-131.

[19] Huang G X, Lin B Q. The research on capital-energy substitution problem in China's industrial sector: A view of meta-analysis. Journal of Financial Research, 2011, 6: 86-96.

[20] Zhang Z Y, Zhao G Q. A Meta-Regression Analysis on the effect of FDI horizontal spillovers in China. Journal of Business Economics, 2012, 4: 80-89.

[21] Wang W J. The spillover effect of FDI in China: A re-analysis based on Meta Regression Analysis. Economic Review, 2010, 1: 133-139.

[22] Görg H, Strobl E. Multinational companies and productivity spillovers: A meta-analysis. Economic Journal, 2001, 11: 723-739.

[23] Wooster R B, Diebel D S. Productivity spillovers from foreign direct investment in developing countries: A meta-regression analysis. Review of Development Economics, 2010, 14(3): 640-655. 